\title{
Social Mobilization to Reduce Vulnerability to Adverse Impacts of Climate Change in the Niger Delta Region of Nigeria
}

\author{
Stephena Udinmade Ighedosa, \\ (MBBS (Benin), PhD (Glasgow), FWACP, ChMC, FNIM, FIPMD) \\ Community Health Department, University of Benin, Benin City, Nigeria
}

Doi:10.19044/esj.2020.v16n21p167 URL:http://dx.doi.org/10.19044/esj.2020.v16n21p167

Abstract

The extensive land-water interface (320 kilometres) between the Niger Delta and Atlantic Ocean exposes the coastal and low-lying areas to climaterelated sea-level rise. This is associated with hazardous ecological changes and unsustainable communities, compounded by social injustice, civil strife, conflicts, insecurity, and the overwhelmingly negative overall effects on health by the environmental degradation caused by petroleum oil spillages, extensive gas flaring, and frequent disastrous gas explosions. This paper focuses on reviewing the vulnerability of the Niger-Delta region to the adverse effects of climate change, and it also explored the potentials of social mobilization to change collective behaviour towards reducing the carbon footprints, build public support for low-carbon climate change policies including focus on green economy, promote ecological resilience, and build sustainable communities. In the context of climate change, the goal of social mobilization is the application of science and policy to 'turn vulnerability to adverse impacts of climate change to resilience'. In the Niger Delta region, social mobilization can assist communities, individuals, groups, and organizations to learn, understand the causes and effects of climate change, and turn vulnerability into resilience. This can be achieved through selfreliance and participation in the planning, implementation, monitoring, and evaluation of sustainable mitigation measures and strategies for adaptation to climate change. Social mobilization enables 'bottom-up' informal, genderdiverse, youth-sensitive, organizational and institutional initiatives for 'good governance', political mobilization against social injustice, and the development of alternative forms of conflict resolution. Efficient social mobilization enables social inclusion of all stakeholders, irrespective of socioeconomic status, to participate in the decision-making process, and also builds skills and capacity to lead happy and healthy lives. Federal and state government policies, in the Niger Delta region, must ensure that their political 
agenda for mitigation measures and strategies for adaptation to climate change adopts social mobilization as an effective tool to turn 'vulnerability to resilience' through a multi-sectoral, multi-jurisdictional, and multidisciplinary participatory approach.

Keywords: Vulnerability to climate change, Building social resilience, Participatory mitigation and adaptation, Partnerships in sustainable development, Social capital

\section{Introduction}

The Niger Delta region in Nigeria is Africa's largest Delta and one of the mega deltas of the world. Geographically, the Niger Delta extends over a total area of 14,000 square miles (36,000square km), stretches for nearly 150 miles $(240 \mathrm{Km})$ from north to south, and spreads along the Atlantic Coast for about 200 miles $(320 \mathrm{Km})$. The present day Niger Delta region includes nine (9) States: Abia, Akwa-Ibom, Bayelsa, Cross River, Delta, Edo, Imo, Ondo, and Rivers (Figure 1; Odjugo, 2011).

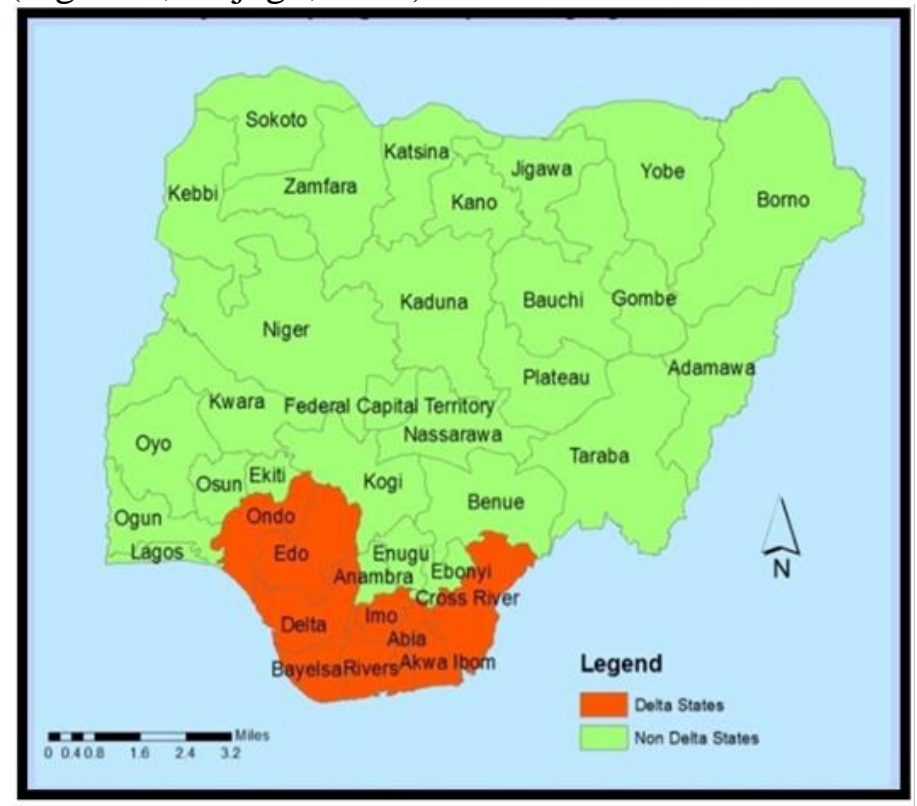

Figure 1. Map of Nigeria showing the Niger Delta Region (Merem et al., 2018, p.8)

\subsection{Economic Development in the Niger Delta Region}

The Niger Delta region constitutes the major oil producing zone in Nigeria. The region comprises of all the six states in the South-South geopolitical zone (Akwa-Ibom, Bayelsa, Cross River, Delta, Edo, Rivers); one state (Ondo) from the South-West geopolitical zone; and two states from the 
South-East geopolitical zone (Abia and Imo) (Figure 1). Of the nine states in the region, only Cross River is not an oil-producing state.

The region is an economic and environmental hotspot, a home to very fertile soil, host of exceptional biodiversity, and rich ecosystems such as mangroves, reed lands, and marshes. It is the food basket of the nation to about 30 million people, constituting approximately 23\% of Nigeria's 200.96 million people that reside in the region. Common Agricultural activities include fishery and forestry. According to the Niger Delta Development Commission (NDDC), the Niger Delta region has a steadily growing population of over 30 million people with a population density of 265 people per square kilometre (Fund for Peace, 2016).

Petroleum and gas mining in the Niger Delta region provides more than 95 percent of the export earnings, accounts for more than 80 percent of the government revenue, and generates over 40 percent of the gross domestic product (GDP) in Nigeria (Omojimite, 2011). Nigeria ranks first place in Africa and 8th place among world oil exporters. Much of the natural gas extracted in oil wells in the Delta region is immediately burned or flared into the air at a rate of approximately 70 million $\mathrm{m} 3$ per day. In $2002,99 \%$ of excess gas was flared in the Niger Delta, constituting the largest single source of greenhouse gas (GHG) emissions on Earth, causing local pollution and contributing to global warming and climate change (Odjugo, 2011). Petroleum and gas are non-renewable forms of energy. Once burned, it cannot be replaced. Its transportation is often associated with oil spills, disastrous explosions, pollution of soils and bodies of water, with special threats to the aquaculture. Petroleum and gas mining, including oil bunkering, enriches despots which leads to suppression of activism and growth of communal conflicts, terrorism, and violence in the Niger-delta region (Ighedosa, 2019).

The Niger Delta region is characterized by developmental contrasts, international controversy over devastating pollution, poverty, genocide, human rights violation, and poor wages. Up to $48 \%$ of employed persons in the Niger Delta earn less than 5,000 Naira per month. The unemployment rates in the Niger Delta are higher than the national average (5\%), except in Abia, Edo, and Ondo States, with other states showing higher rates, e.g., 18.2\% in Akwa Ibom, $19.1 \%$ in Rivers, and $16.6 \%$ in Cross Rivers States (Ebegbulem et al., 2013).

The location of the Niger Delta, directly on the Gulf of Guinea on the Atlantic Ocean in Nigeria, provides a land-water interphase for intense economic activities, including local, regional and international ports and harbours, and rapidly growing cities. 


\subsection{Climate Change}

Climate change is a global phenomenon with adverse impact especially in the coastal and low lands of the mega-delta regions of the world. The climate change parameters projected for the mangrove zone in Nigeria (Table 1) relates almost exclusively to the Niger Delta region of Nigeria.

Table 1. A summary of the projected trends in the key climate change parameters for Nigeria is presented in the following table by ecological zone

\begin{tabular}{|c|c|c|c|c|}
\hline Climate variables & $\begin{array}{l}\text { Mangrove } \\
\text { zone }\end{array}$ & $\begin{array}{l}\text { Rain } \\
\text { forest }\end{array}$ & $\begin{array}{l}\text { Tall } \\
\text { grass } \\
\text { (savanna) }\end{array}$ & $\begin{array}{l}\text { Short } \\
\text { grass } \\
\text { (Sahel) }\end{array}$ \\
\hline Temperature & $\uparrow$ & $\uparrow$ & $\uparrow$ & $\uparrow$ \\
\hline Rainfall amount & $\uparrow$ & $\uparrow$ & $\downarrow$ & $\downarrow$ \\
\hline Rainfall variability & $\uparrow$ & $\uparrow$ & $\uparrow$ & $\uparrow$ \\
\hline Extreme rainfall events -droughts & Likely & Likely & $\uparrow$ & $\uparrow$ \\
\hline $\begin{array}{l}\text { Extreme rainfall events -storms } \\
\text { and floods }\end{array}$ & $\uparrow$ & $\uparrow$ & Likely & Likely \\
\hline Sea level rise & $\uparrow$ & NA & NA & NA \\
\hline
\end{tabular}

The Earth's climate is determined by complex interactions between the Sun and the domains of the Earth. The Earth is a complex system consisting of five domains or Spheres, namely: the geosphere, hydrosphere, cryosphere, biosphere, and the atmosphere. The geosphere consists of the crust, the mantle, and the core of the earth; the surface soils, rocks, and sediments, found in the outer part of the Earth, constitute the lithosphere. The hydrosphere includes the seas, lakes, clouds and all the waters in, on, and around the earth. The cryosphere is the frozen world including sea ice, lake ice, river ice, snow cover, glaciers, ice caps, ice sheets, and frozen ground. The biosphere consists of both the living things and their non-living derivatives, such as fossil fuel. The atmosphere is the envelope of gases that surrounds, protects, and makes the earth habitable. The atmosphere comprises of five layers namely: the troposphere, stratosphere, mesosphere, thermosphere, and exosphere which is based on temperature. The exosphere is the farthest and hottest layer at about $500 \mathrm{~km}$ above the Earth's surface.

Weather is the continuously changing condition of the lower layer of the atmosphere, and it is usually considered on a time scale that extends from minutes to weeks. Climate is the state of the lower atmosphere, and the associated characteristics of the underlying land or water, in a particular region, usually spanning at least several years (WHO, 2003). Climate is the "average weather" and is measured as the statistical mean of the climatic variables, namely: temperature, precipitation, and wind over a period of time ranging from months to thousands or millions of years. The classical period is 30 years as defined by the World Meteorological Organization (WMO) 
(World Meteorological Organization, n.d.). Climate has changed significantly when compared to the pre-industrial era. The Sun is nature's principal driving force of weather and climatic variables (temperature, rain and wind) as shown in Figure 2.

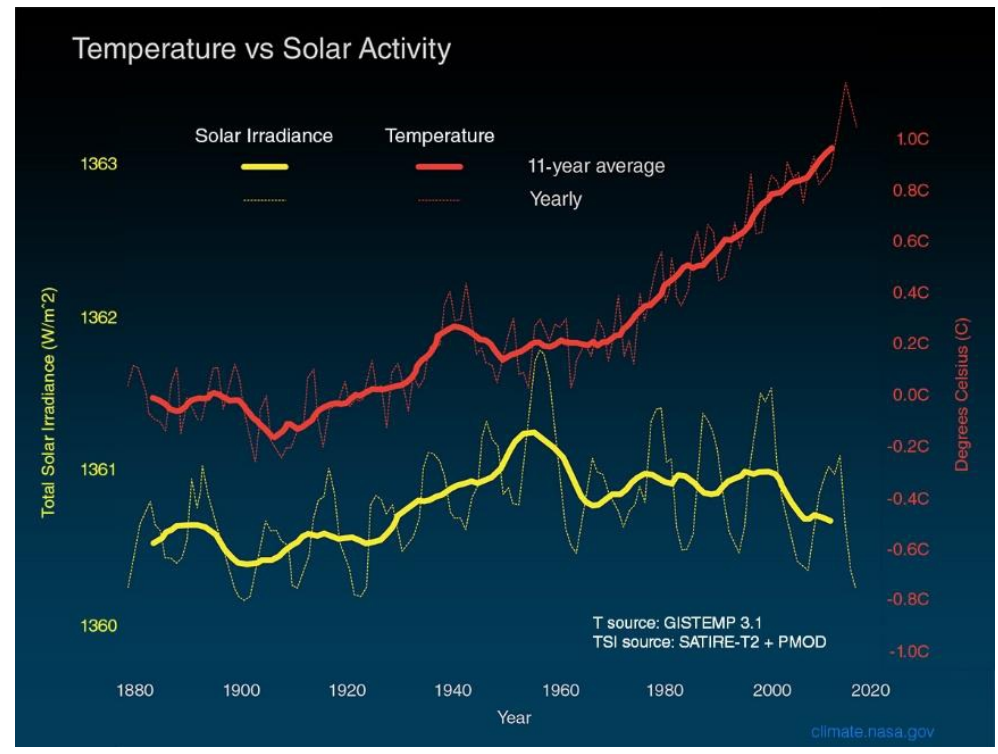

Source: climate.nasa.gov

Figure 2. Graph Showing Changes in Solar Radiance and Temperature over Time Source: https://climate.nasa.gov/internal_resources/1802/

\subsubsection{Climate Change}

The UNFCCC defines 'climate change' as a change of climate which is attributed directly or indirectly to human activity that alters the composition of the global atmosphere. This is in addition to natural climate variability observed over comparable time periods (UNFCCC, 2011). Climate change is associated with increased variability, frequency, and intensity of climatic variables, namely: temperature, precipitation, and wind. Climate change has also been associated with global warming. During the twentieth century, world average surface temperature increased by approximately $0.60 \mathrm{C}$ and approximately two-thirds of that warming had occurred since 1975 as shown in Figure 2. Climatologists forecast further warming during 2020 and beyond (WHO, 2003).

The Intergovernmental Panel on Climate Change (IPCC) has stated that there is new and stronger evidence that most of the warming observed over the last 50 years is attributable to direct or indirect impacts of human or anthropogenic activities on the biophysical environments, ecosystems, biodiversity, and natural resources (Smithson, 2002). Human activities, especially fossil fuel combustion and forest burning, associated with emissions of greenhouse gases (GHGs) increase the atmospheric concentrations of 
energy-trapping gases, with the potential of amplifying the natural "greenhouse effect" that makes the Earth habitable. The most culpable heattrapping GHGs include: Carbon dioxide (CO2), Water vapour, Methane (CH4), Nitrous oxide (N2O), Halocarbons, and Ozone (O3) (UNFCCC, 2011).

Climate change signifies that, today, the Earth's biophysical and ecological systems are altered at the planetary scale. This is also evidenced by stratospheric ozone depletion, accelerating losses of biodiversity, stresses on terrestrial and marine food-producing systems, depletion of fresh water supplies, and the global dissemination of persistent organic pollutants. The IPCC's Third Assessment Report projected that, as we continue to change atmospheric composition, global surface temperature will rise by 1.4 to $5.80 \mathrm{C}$ in this century, along with changes in precipitation and other climatic variables (Smithson, 2002). International agreements on global environmental issues of climate change considered the principles of sustainable development, which was proposed in Agenda 21 and the UNFCCC-driven agreements on complete transformation of societies. These include the "precautionary principle", the principle of "costs and responsibility" (the cost of pollution or environmental damage should be borne by those responsible), and equity - both within and between countries and over time (between generations) (Katherine, 2009; UNFCCC, n.d.; UNFCCC, 2011).

\subsubsection{Mitigation and Adaptation}

Mitigation measures and strategies for adaptation to climate change are global interventions agreed upon by the United Nations to reduce vulnerability to the overwhelming negative impacts of climate change on the social and environmental determinants of the wellbeing of humanity. This includes clean air, safe drinking water, sufficient food, and sufficient shelter. Health promotion, disease prevention, and building resilience through social mobilization are central to successful mitigation measures and strategies for adaptation (Social Mobilization, 2019).

Mitigation, in the context of climate change, refers to policies and measures to reduce greenhouse gas emissions or enhance 'sinks' of greenhouse gases. A 'Sink' is any process, activity or mechanism, which removes a greenhouse gas, an aerosol or precursor of a greenhouse gas from the atmosphere. Forests and other vegetations are considered sinks because, they remove carbon dioxide from the atmosphere, through photosynthesis. Mitigation constitutes primary intervention to avoid, reduce, delay or reverse hazardous impact of climate change, including advocacy of renewable energy, such as wind and solar power, that are not depleted when used (UNFCCC, n.d.). Adaptation is a secondary intervention to climate change that refers to adjustment in response to actual or expected climatic stimuli or their effects, which moderates harm or exploits beneficial opportunities (Katherine, 2009; 
Thornes, 2002). Climate-related mitigation measures and strategies for adaptation are urgent interventions that require integrated and simultaneous implementation.

\subsection{Hazardous Impacts of Climate Change}

Impacts of climate change are categorized as 'actual' or 'projected future impacts' (Ighedosa, 2019).

\subsubsection{Actual Impacts of Climate Change}

Increasing global warming can lead to the following: increasing acidification of the oceans with a progressive decrease in $\mathrm{pH}$; contraction of Snow cover and widespread increases in thaw depth over most permafrost regions; shrinking of sea ice in both Arctic and Antarctic regions, with risks of disappearance of most of the Arctic late summer sea ice by the later part of the 21 st century. It can also lead to more frequent and more intense extreme weather variability, with extreme heat-waves, heavy precipitation, catastrophic flooding, and disastrous wind cyclones; Increased likelihood of precipitations in high latitudes; decreased likelihood of precipitations in most sub-tropical regions; trends towards earlier 'greening' of vegetation and longer thermal growing season; and changes in marine and freshwater biological systems associated with rising water temperatures, such as increased salinity, fall in oxygen levels, and circulation patterns that carry oxygen-rich water to the deeper ocean which have an impact on fishery and aquaculture. Other effects of increased global warming are increase in the frequency of droughts and floods, leading to decrease in local crop production in all regions, especially in subsistence sectors, at low latitudes. In addition, even slight warming decreases yields in seasonally dry and tropical regions.

However, moderate warming benefits food production, especially cereal crops and pasture yields, in mid to high latitudes. Global warming may reduce winter deaths in temperate climates. Extreme heat, natural disasters, and variable rainfall patterns associated with climate change have a negative impact on the social and environmental determinants of health, including: clean air, safe drinking water, sufficient food, and sufficient shelter. High temperatures raise the levels of ozone and other pollutants in the air which have an overwhelming negative overall effect on health. Extreme weather events, including flooding and droughts, have the potential to affect patterns of infection, famine, internal displacements, and the disruption of supply of medical and health services. There is evidence that climate change is associated with increased risks of communicable diseases, malnutrition, and undernutrition with exacerbation of cardiovascular and respiratory diseases, by rising levels of ozone and other pollutants in the air, due to extreme heat (WHO, 2003). 


\subsubsection{Projected Future Impacts}

There are predictions that anthropogenic global warming and sea-level rise will continue for centuries, due to the time scales associated with climate processes and feedbacks, even if greenhouse gas emissions were to be stabilized. There are concerns that the net carbon intake by terrestrial ecosystems is likely to peak before the middle of the 21st century. After then it will weaken or even reverse, thus amplifying climate change. Projected future impacts of continued global warming include: increase in frequency and intensity of precipitation events, with risks of flooding will increase risks of water stress; temperature increases, with intensification of dry spells in drought affected areas, with more frequent and more persistent increase of extensive wildfires, globally; and increasing sea level rise is expected to change the distribution and production of particular fish species due to continued warming, with adverse effects for aquaculture and fisheries (Ighedosa, 2019; Intergovernmental Panel on Climate Change (IPCC), 2014; Katherine, 2009).

Continued global warming may be associated with species extinctions and major biome changes, due to multiple stresses, in vulnerable ecosystems, including: continental tundra, boreal forest, mountain and Mediterranean-type ecosystems; coastal mangroves and salt marshes; and oceanic coral reefs and the sea-ice biomes. Consequently, progressive acidification of the oceans has a negative impact on marine shell-forming organisms, such as corals and their dependent species.

Geographically, all populations will be vulnerable to the future negative impacts of climate change, particularly small islands, coastal regions, megacities, and mountainous and polar regions. Children, elderly people, and people with infirmities or pre-existing medical conditions, who live in poor countries, are among the most vulnerable to the resulting health risks. Also, they will be exposed longer to the health consequences because of the weak health infrastructure (WHO, 2003).

Climate change is expected to cause approximately 250,000 additional deaths per year between 2030 and 2050, including: 38,000 deaths due to heat exposure in elderly people, 48,000 deaths due to diarrhoea, 60,000 deaths due to malaria, and 95,000 deaths due to childhood under nutrition (WHO, 2003).

\subsubsection{Social and Economic Impacts of Climate Change}

Increasing frequency and intensity of extreme weather events put severe pressure on food security and food safety; access to potable water; loss of biodiversity, aquifers, soil fertility with risks of protein-energy malnutrition; loss of livelihoods, habitats, public infrastructures, and increased morbidity and mortality. Climate change was estimated to be responsible in the year 2000 for approximately $2.4 \%$ of worldwide diarrhoea, $6 \%$ of malaria 
in some middle income countries, and $7 \%$ of dengue fever in some industrialized countries, especially among vulnerable groups, such as children, the aged, pregnant women, and the chronically ill. Other socio-economic hazards of climate change include negative impacts on ecosystems as shown in Figure 3 (Rodgers \& Vaughan, 2002).

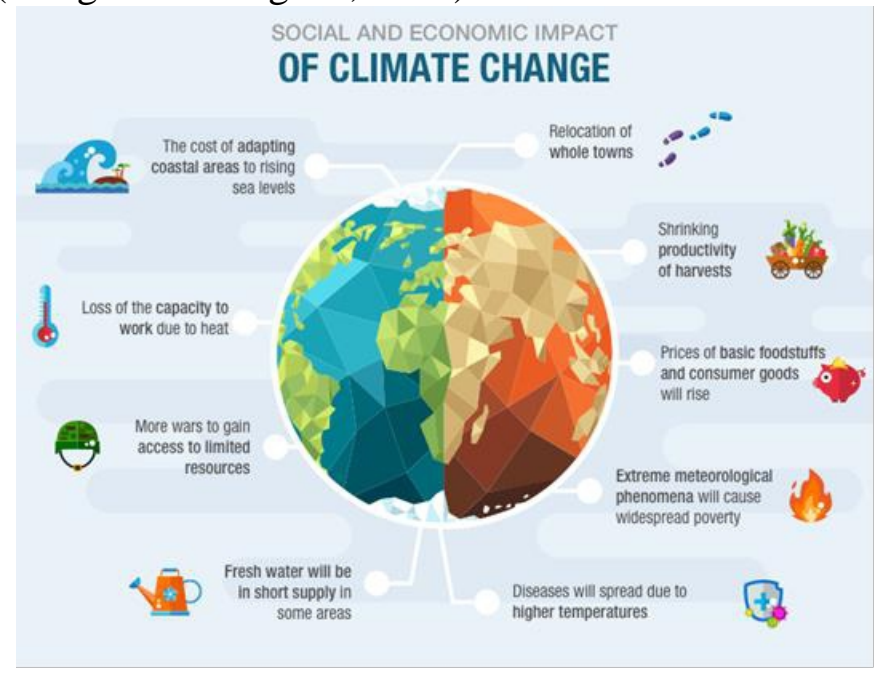

Figure 3. Social and economic impact of Climate change

Source: Iberdrola. (2019, October 9). How is climate change affecting the economy and society? Retrieved from https://www.iberdrola.com/environment/impacts-of-climate-change

\subsection{Social Mobilization}

Social mobilization is a process of engaging a wide range of traditional, community, civil society, and opinion leaders, around a common cause or issue, towards a developmental behaviour change. Community engagement, on the other hand, is when individuals or groups in a defined community get together to focus on collective or group participation to achieve a particular goal, not necessarily any particular behaviour. Social mobilization often emerges from a sense of shared grievance and injustice, and it makes visible alternative ideas and concepts about the forms that society (and development) should take. Social mobilization expands beyond community engagement as a focus, and it also reaches out to nongovernmental organizations, professional groups/networks, youth groups, women's groups, community-based organizations, faith-based organizations, professional networks, and the private sector to catalyse these different groups to take action and or support change in a common cause, e.g., building resilience to impacts climate change. Through alliance- building and partnerships, often combined with media campaigns, social mobilization also engages and motivates various partners at international, national, and local levels to raise the awareness of and demand for a particular development objective. It also provides sustainable and multifaceted solutions to broad 
social problems through a multi-sectoral, multi-jurisdictional, and multidisciplinary participatory approach (Ighedosa, 2019; UNICEF, 2015).

The goal of social mobilization is to facilitate change through an interdisciplinary approach that ensures ownership of the Agenda by civil society. Social mobilization brings together all societal and personal influences to raise awareness of and create demand for specified services, assist in the delivery of resources and services, and to cultivate sustainable individual and community involvement. Social mobilization employs collaboration of members of institutions, community partners, and organizations to reach specific groups of people for intentional purposive dialogue.

Sustainable social and behaviour change requires collaboration at multiple levels, as partnerships yield stronger impacts than isolated efforts. Consequently, strategies of social mobilization include using advocacy to mobilize resources, and media and leaders to raise awareness, create public spheres for debate, and build partnerships.

The process of social mobilization is an open and socially inclusive conversation involving young people, women, people living with disabilities, civil society leaders and activists because ownership of the Agenda by civil society is critical for its success and sustainability.

Social mobilization is a global tool that promotes effective public, public-private, and civil society partnerships that build on the experience and resourcing strategies of partnerships, for the explicit implementation of sustainable development goals (SDGs) (WHO, 2019).

Social mobilization is the process of empowering communities, individuals, groups, and organizations to identify their own resources, felt needs, real needs (summation of: normative, felt, expressed and comparative needs), strengths, including leadership skills for creative development. Empowerment also builds Alliance and Partnerships with influential individuals, civil societies, public and private agencies and donors. This is aimed at producing a 'Social Capital' that provides the resources and finance for the planning, implementation, monitoring, and evaluation of sustainable development. 'Social Capital' drives and funds the commitment of the network of relationships among people and organizations, that live and work in a defined geographic region, to efficiently and effectively achieve sustainability of the desired change.

In the context of climate change, the goal of social mobilization is to 'turn vulnerability to resilience'. Social mobilization empowers people to learn about climate change and their vulnerability to hazardous impacts and to understand their roles in mitigation measures and strategies for adaptation. Social mobilization provides an opportunity to use science and policy to 'turn vulnerability to resilience' through social alliances and partnerships between 
local stakeholders (communities, individuals, groups and organizations) with academic institutions (experts from the physical and sciences, economics, health/demographics, management and policy), capacity building leaders from research institutions, government agencies, and non-profit organizations to ensure the recovery and sustainable development of the Niger Delta region (Foufoula-Georgiou, 2013).

Furthermore, social mobilization builds the capacity of communities, individuals, groups, and organizations to take ownership of the decisionmaking process. This can be achieved through full participation in the planning, implementation, monitoring, and evaluation of activities to build their own resilience, mitigation measures, and adaptation to both the actual and projected impacts of climate change.

Partnerships yield stronger impacts than isolated efforts. The goal of social mobilization is to promote, protect, and support self-resilience through participatory development at the grassroots level, towards transformation of economies, in line with the sustainable Development Goals (SDGs). Participatory development enables the involvement of would-be beneficiaries to own the decision-making processes, such that they are both the actors and agents of change. This is essential for sustainable development. Participation of beneficiaries in the decision-making process guarantees the sustainability of projects and programmes, even in the absence of supportive partners.

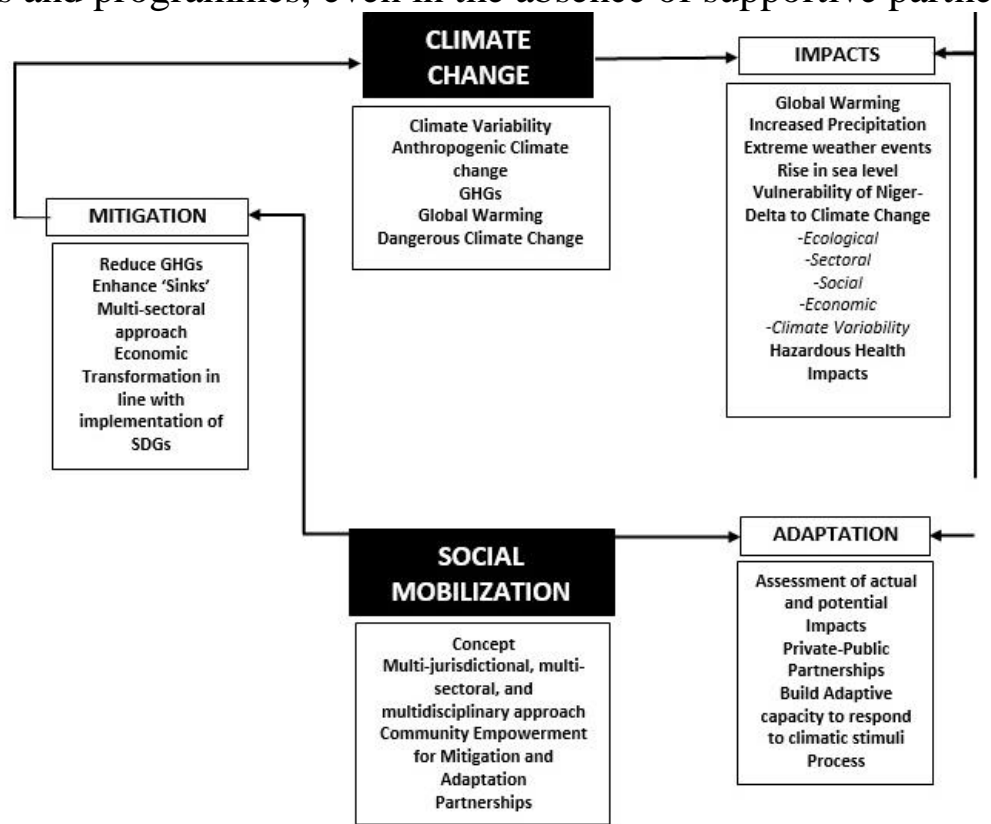

Figure 4. Conceptual Framework of Social Mobilization for Mitigation measures and Adaptation to Climate Change

Source: Ighedosa SU (2020). Community Mobilization for Mitigation Measures and Adaptation to Climate Change. Nigerian Journal of Applied Science. 38: 34-48. ISSN 0795 1353. 
Consequently, sustainable development requires the engagement of traditional, community, civil society, and opinion leaders around a common behaviour, issue or decision that affect their lives. Social Mobilization (SM) brings together all societal and personal influences to raise awareness of vulnerability and exposure to actual impacts of climate change and risks of hazardous projected impacts, especially in the coastal and low-lying areas of the Niger-delta region. It creates demand for information, assists in the delivery of resources and services, and cultivates sustainable individual and community involvement (Social Mobilization, 2019). SM builds the capacity of communities, individuals, groups and organizations for ownership of the decision-making process to plan, implement, monitor, and evaluate activities through full participation in the protection, promotion, and support of their own health and development.

Appropriate response to vulnerability to hazardous impacts of climate change consists of building resilience and adaptation capacity of individuals and communities in the Niger-Delta region. Social mobilization is the most sustainable opportunity for efficient and effective empowerment of individuals, communities, and organizations in the Niger Delta region. This helps them to think and better understand their vulnerability to the impacts of climate change. It also helps them to organize and build resilience, skills, and capacity to lead happy and healthy lives through participatory bottom-up approach with their own initiative and creativity (Figure 4).

\section{Vulnerability To Hazardous Impacts Of Climate Change \\ 2.1 Background}

Vulnerability is the susceptibility of a person, population, or place to harm in a specified time. Vulnerability is dynamic and variable and can be influenced by climate change (e.g., extreme weather events affecting health infrastructure). Vulnerability to climate change is the degree to which a system is susceptible to, or unable to cope with, the adverse effects of climate variability, intensity, and change (IPCC, 2007).

From a health perspective, vulnerability can be defined as the summation of all risks and protective factors that ultimately determine whether individuals, groups, communities and/or regions experience adverse health outcomes due to climate change (Balbus \& Malina, 2009).

\subsection{Vulnerability of the Ecosystem}

An ecosystem is a large community of living organisms (plants, animals and microbes), and the physical environment that support their nutrient and energy cycles. High exposure to sea level rise (intrusion of saline sea water into fresh water system), storm surges, coastal erosion, and river flooding due to global warming is associated with ocean acidification, rising 
water temperatures, increasing salinity, and decreasing oxygen levels with the potential to impact negatively on the marine ecosystem leading to loss of biodiversity, aquifers and soil fertility, aquaculture and fisheries in the Niger Delta. The vulnerability is exacerbated by increasing human-induced environmental degradation in coastal and low-lying areas due to oil spillages and gas flaring (Cazenave \& Cozannet, 2014; Crutzen, 2002; McGranahan et al., 2007; Niger Delta Development Commission, 2006; Parry, 2007).

The Vulnerability of the ecosystems impacts on the physical, social, and economic health of individuals, groups, and communities due to hazardous impacts associated with climate change including extreme flooding events, life threatening sea surges, coastal erosions, injury and death and illness from extreme weather events (increased temperature and extreme precipitation and flooding); air pollution related illness; water borne diseases; vector borne illness; heat-related illness and deaths; cold related deaths; human exposure to chemicals; disturbance of natural and managed foodproducing ecosystems, especially ocean fisheries; and population displacement due to physical and chemical hazards (oil spillages and gas explosions), land loss, economic disruption, and civil strife with excess morbidity and mortality. Health risk of climate change is the product of exposures to hazard and local vulnerability (Katherine, 2009; Lindgren \& Gustafson, 2001; Pascual et al., 2000).

Prolonged flooding can shorten farming season, increase risks of displacement, water contamination (with chemicals and infective agents), overcrowding with vulnerability to excess morbidity and mortality from malaria, and increase breeding of disease-causing vectors (e.g., mosquitoes) (Crutzen, 2002). Increased frequency of precipitation and Equatorial Rainforest climate increases the magnitude of vulnerability to climate change. Flooding arising from increased precipitation increases risks of community displacement often associated with malnutrition, diarrhoea diseases, respiratory diseases, and possible land disputes. Increased sea level rise can lead to intrusion of saline sea water into fresh water system with risks of contamination of potable water and alterations of ecosystems.

\subsection{Social Vulnerability (SV) to Hazardous Impacts of Climate Change}

Social Vulnerability (SV) measures the intrinsic predispositions or risks that make a biophysical system susceptible to adverse impacts from external hazards. Social vulnerability to climate-related impacts is increased by inefficient mitigation measures and fragile adaptation capacity, including emergency preparedness and poor access to meteorological services. The 200mile long, low-lying, and land-water interface with the Atlantic Ocean increases risks of Niger Delta vulnerability to hazardous threats from climate- 
related sea-level rise, cyclones, river flooding, storm surges, salinization, coastal erosion, and sediment starvation. Vulnerability of the Niger Delta is compounded by human or anthropogenic activities such as rapid urbanization, agricultural overuse, oil mining, oil bunkering, oil spillages, environmental degradation, and gas flaring with emission of GHGs (Ighedosa, 2019; Onokerhoraye, 2011).

Small islands, most especially, would be vulnerable to climate change due to exposure of population, residential and public infrastructure, potable water supplies, educational and health facilities to destruction and/or contamination by projected extreme climatic variables. Increased risks of extreme weather events, e.g., flooding, is often challenging to the poor, especially those dwelling in rapidly expanding communities located near rivers and coasts, and who use or depend on climate sensitive resources, e.g. aquaculture. Ocean acidification and warming have the potential to impact negatively on the aquaculture and fisheries, which constitute their major occupation and main source of nutritional protein. In addition, more intense and/or more frequent extreme weather events increases their economic losses and social disruption (Cazenave \& Cozannet, 2014; Ighedosa, 2019; IPCC, 2014; McGranahan et al., 2007; Parry, 2007; Smithson, 2002; UNFCCC, 2011).

\section{Social Mobilization To Reduce Vulnerability To Climate Change 3.1 Background}

Social mobilization (SM) can facilitate Niger Delta regional response to climate change through an interdisciplinary approach that ensures community ownership of the agenda. Social mobilization is the backbone for strengthening partnerships that remain accountable to people's overlapping multi-sectoral needs. Social mobilization harnesses the growing power of civil societies to advance community and regional development. It offers a powerful stimulus to form alliances across constituencies that have traditionally worked in parallel to create opportunity for all people to participate in meaningful decision-making.

Social mobilization utilizes the collective strengths of the partnerships of stakeholders and community participation in decision making to build 'resilience'. In the context of climate change, social mobilization is a tool for the empowerment of individuals and communities, with the skills and capacity, to turn vulnerability to resilience. Capacity for resilience includes: improving political will; increasing level of awareness of climate change (cause, effects, mitigation and adaptation); reducing poverty; increasing wealth index; reducing inequality; reducing political marginalization; improving food security; increasing access to insurance; improving housing quality; and increasing utilization of meteorological services and building 
adaptive capacity of individuals, groups, and communities to the adverse impacts of climate change.

\subsection{Goal and Objectives}

The goal of social mobilization is to 'turn vulnerability to resilience' through a bottom-up, multi-sectoral, multi-jurisdictional, and multidisciplinary participatory approach that establishes partnerships between vulnerable communities and academic institutions (experts from the physical and sciences, economics, health/demographics, management and policy), local stakeholders and capacity building leaders from research institutions, government agencies, and non-profit organizations to use science and policy to implement mitigation measures and strategies for adaptation to climate change (Foufoula-Georgiou, 2013).

The specific objectives include:

i. Social mobilization (SM) is an essential primary step for socioeconomic transformation and community development. SM empowers people to think and understand their issues or decisions that affect their lives, and to organize and initiate action for recovery or desired change, through their own initiative and creativity (UN-Habitat Regional Office, 2008).

ii. SM can ensure social inclusion for a just, gender-diverse, youthsensitive, profitable, and sustainable climate-sensitive equitable decision for the sustainable transformation of the Niger Delta region.

iii. SM also provides opportunity for the full participation of the rich, the poor, and the politically marginalized in the planning, implementing, monitoring, and evaluation of transformational interventions at the grass-root level (Geldof, 1994).

iv. SM enables individuals and communities to own, implement, monitor, evaluate, and ensure the sustainability of programmes and projects, even in the absence of external partners.

v. SM builds 'Social Capital' to provide resources for real needs for sustainable development.

vi. SM ensures the engagement of traditional, community, civil society, and opinion leaders in the dialogue about common behaviour, issues, or decision that affect their lives.

vii. SM empowers participatory leadership to effectively assess, analyse, plan, facilitate, implement, and evaluate interventions to change common behaviour, issues, or decisions that affect their lives.

viii. SM builds capacity of communities to reach out to CBOs, NGOs and Donors, and motivate them to take action and /or support behaviour change, in a common cause, to reduce vulnerability to adverse impacts of climate change in the Niger Delta region. 
ix. SM provides an opportunity to build social alliances and partnerships between local stakeholders (communities, individuals, groups and organizations) and academic institutions (experts from the physical and sciences, economics, health/demographics, management and policy); capacity building leaders from research institutions, government agencies, and non-profit organizations can collectively apply policy and science to ensure the recovery and sustainable development of stakeholders and vulnerable communities in the Niger Delta.

x. SM builds the capacity of local stakeholders, to take ownership of the decision-making process, through their full participation in the planning, implementation, monitoring, and evaluation of mitigation measures and adaptation to actual and projected impacts of climate change.

\subsection{Process of Social Mobilization}

Operationally, social mobilization involves advocacy, needs assessment, establishing a community mobilization group (alternative leadership), setting of objectives, climate change communication, identification of vulnerable groups, and development of a plan of action (POA) that does not interfere with existing statutory health systems, building alliances and partnerships, community engagement to create awareness of vulnerability, building capacity for identified gaps in resources, implementation of POA, monitoring, and evaluation (Figure 5).

A joint multi-sectoral, multi-jurisdictional, and multi-disciplinary, gender-diverse and youth-sensitive team will be required to drive the social mobilization process, in the Niger-Delta region. The team should have representatives drawn from all the nine states within the region, including relevant Federal Government agencies, such as National Oil Spill Detection and Response Agency (NOSDRA), Federal Environmental Protection Agency (FEPA), Federal Ministry of Environment, and Niger Delta Developmental Commission (NDDC).

\subsubsection{Advocacy}

Advocacy is an important step in setting up community-based activities. Advocacy is the process of presenting the initiative for social mobilization, at central and local levels, to relevant stakeholders, targeting high-level decision-makers, influential persons, and organizations in the Public, Traditional, and Private Sectors, to solicit their involvement in community action to develop and implement mitigation measures and strategies for adaptation to climate change. Advocacy engages and motivates various partners at national, regional, and local levels for Community Action. 
Advocacy mobilizes political commitment that is critical for establishing sustainable multi-sectoral mitigation measures and adaptation strategies. Advocacy should include consultations of relevant public or government agencies to ensure that the engagements of civil societies to reduce social vulnerability do not interfere with public (national or state) policy on mitigation measures or adaptation strategies to climate change.

Mobilization of civil societies, with building of cross-constituency partnerships for overlapping social injustices and common community demands, promotes cooperation amongst civil societies (CSOs). Mobilization of appropriate organizations of the UN system, including United Nations Framework Convention on Climate Change (UNFCCC), WHO and UNICEF, to support the development of win-win policies and programmes for efficient and effective community mobilization for the reduction of hazardous impacts of climate change.

Mobilization of the private sector ensures effective public-privatepartnership (PPP), encourages involvement of all stakeholders, builds credibility, strengthens political will, increases 'Social Capital, and assures sustainability of mitigation measures and adaptation strategies.

Mobilize Media platforms including, Print Media (Newspapers, Magazines), Broadcast Media (TV, Radio), Outdoor or Out of Home (OOH), and the Internet to engage a wide population on decision-making processes related to reduction of vulnerability to the adverse impacts of climate change in the Niger Delta region.

The leadership of all the communities and constituencies, that are vulnerable to the adverse impacts of climate change in the Niger Delta region, should be mobilized to respond to the developmental injustices. This can be achieved by supporting their capacity for self-determination to organize and build cross-cutting alliances amongst collaborating change agents.

The academic and research institutions should be mobilized to develop and improve methods to evaluate social mobilization using an evidence-based approach. The expertise of sociologists is needed to develop valid and reliable tools required to process the social and organizational aspects of social mobilization for climate change action.

\subsubsection{Needs Assessment}

The advocacy team should set up a 'Task Force' to conduct a local study with a situation analysis that generates a demographic profile which identifies: available resources; hazardous climate-related impacts in the community; vulnerable groups; existing initiatives; felt needs (expressed and comparative changes deemed necessary to correct perceived injustices, in community development); real needs (information, skills and resources required for sustainable development); and strengths, including leadership 
skills for creative development (Centers for Disease Control and Prevention, n.d.).

Vulnerable minority groups, including immigrants, seasonal migrant workers, refugees, asylum seekers, cross-border populations, nomadic populations, populations in remote areas or "difficult-to-reach" population groups, ethnic minorities, marginalized indigenous populations, homeless people, the elderly, children, the chronically ill on medications, injecting drug users, and pregnant women, etc., should be identified. The need(s) of each group should be carefully defined and located or mapped. Health priorities should also be identified with access to health services dully assessed. Barriers to access, namely: economic, political, social, geographic, or ethical factors to mitigation and/or adaptation measures should be determined. The health care providers who normally work with these groups should be linked up with existing social services and local NGOs for collaborative interventions, monitoring, and evaluation (WHO, 2009).

The task force should draft a policy guidance and Plan of Action (POA) including clear goals and objectives for local mitigation measures and adaptation to climate change, essential for the full transformation of economies of the communities, in line with sustainable development goals (SDGs). The POA should include specific role definitions for all stakeholders participating in the strategic implementation of the social mobilization. The POA should provide guidance for the constitution of a 'Community Mobilization Group' (Alternative leadership). This approach promotes community ownership of the initiative, and it also encourages the community's active involvement and shared responsibility for the initiative. 


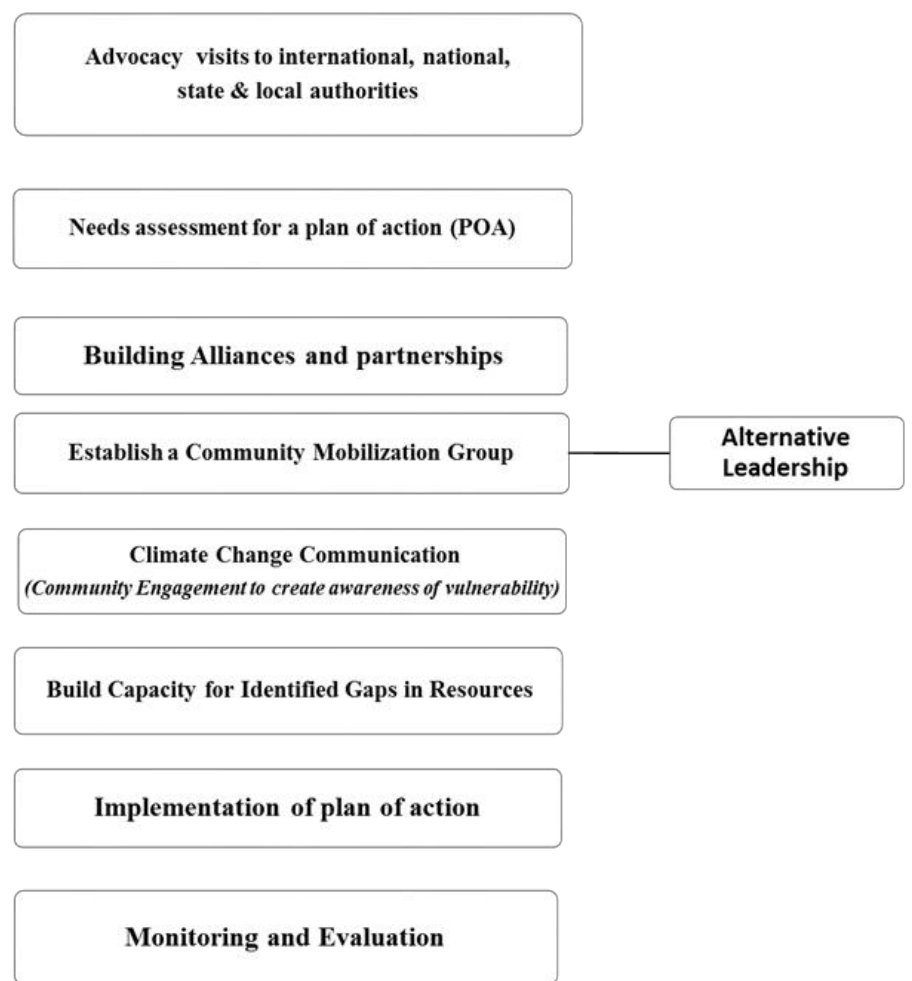

Figure 5. Process of Social mobilization for Mitigation and Adaptation to Climate Changes Adapted from Source: Ighedosa SU (2020). Community Mobilization for Mitigation Measures and Adaptation to Climate Change. Nigerian Journal of Applied Science. 38: 3448. ISSN 0795-1353.

The report of the task force should include a budget that evaluates both the available financial resources and needed resources based on the needs assessment. Activities in the plan of action (POA) should be prioritized based on the funding that is available or will be available in the future. Resources should be categorised (e.g., grants, in kind services, volunteers, etc.). Maintaining the budget by categories will also help to keep track of deadlines e.g., grant proposal submission to ensure that projects can be completed with the available resources. Depending on the complexity of the budget, the taskforce should indicate the need for a grant writer for the social mobilization effort and a treasurer/ accountant to facilitate accountability. Thus, this will encourage partners and donor agencies to provide and sustain financial support for community projects. Consequently, the budget document should reflects activities, costs, and probable sources of financial support (Centers for Disease Control and Prevention, n.d.; Huberman et al., 2014; WHO, 2009). 


\subsubsection{Building Alliances and Partnerships}

Build alliances and Partnerships with NGOs, International/Local, FBO, CBOs, and Professional groups and donors (International \& Local) (Figure 6) in order to generate resources, including appropriate technology and finance.

Establish a list of all NGOs, FBOs, CBOs, including newly arrived NGOs/organizations, professional groups and donors, and distribute widely among stakeholders and partners.

\subsubsection{Climate Change Communication}

Expert trainers should design or adapt standard climate change communication tools, tailored to suit the local context and to raise the awareness of and demand for a particular development objective and to provide multi-faceted solutions to the multi-factorial vulnerability to hazardous impacts of climate change (UNICEF, n.d.).

This involves creating awareness of vulnerability to climate change, cause, effects, mitigation, and adaptation (challenges and opportunities) to climate change, using media campaigns and community leaders, to raise awareness and create public spheres for debate on climate change related issues (UNICEF, 2015). There should be wide distribution of education messages through information channels, including the 'town crier' or 'bellman' that are accessible to all stakeholders.

\subsubsection{Build Capacity for Identified Gaps in Resources}

Social mobilization takes advantage of the information documented in the community profile to identify gaps in resources, notably: political will, information, skills, technology including housing quality, and income (Figure 6). SM takes advantage of knowledge of identified gaps to plan, build 'Social Capital' and implement empowerment programmes and projects, to reduce poverty, and promote equity, equality and quality life. SM also eliminates political marginalization, promote food security, increase access to insurance and quality housing, and promote utilization of meteorological services to turn vulnerability to resilience to climate change.

Capacity building would be achieved through a series of 10-day Training of the Trainer (TOT) and five-day Participatory Development Workshop (PDW) (Geldof, 1994) on the following themes: regional transition to renewable energy; sustainable and resilient infrastructure and cities; sustainable agriculture and management of forests and oceans; resilience and adaptation to climate impacts; alignment of public and private finance with a net zero economy; strengthening of economies, job creation, promoting cleaner air, preserving natural habitats and biodiversity with protection of environment; ending subsidies for fossil fuels and high-emitting agriculture; 
shifting towards renewable energy, electric vehicles and climate-smart practices; carbon pricing that reflects the true cost of emission from climate risk to health hazards of air pollution; transition from fossil fuel driven economy to new technologies based on more affordable solar and on-shore wind engineering solutions; accelerating enforcement of sanctions, including closures of industries operating with high carbon emissions, including the closure of coal plants, halting the construction of new ones, and replacing jobs with healthier alternatives, for a just, inclusive and profitable sustainable climate sensitive socio-economic transformation; improving access and patronage of Meteorological services; and emergency preparedness for extreme weather events, e.g., flooding, heat waves, cyclones oceanic surges, massive oil spillages, and gas explosions.

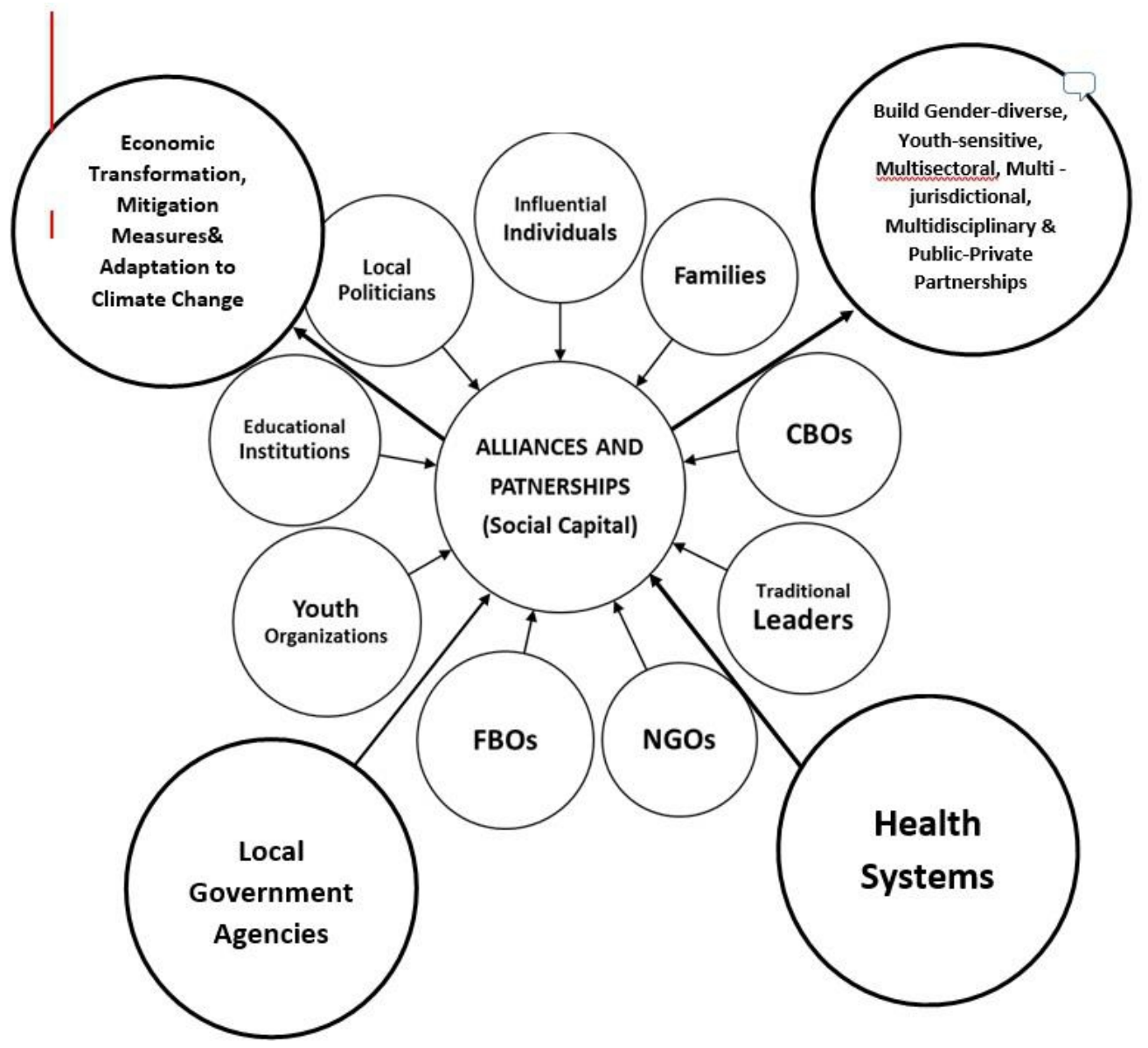

Figure 6. Conceptual Framework for Social Mobilization of Alliances and Partnerships to create 'Social Capital'

Source: Ighedosa SU (2020). Community Mobilization for Mitigation Measures and Adaptation to Climate Change. Nigerian Journal of Applied Science. 38: 34-48. ISSN 07951353. 


\subsubsection{Ensure Full Participation of Local Stakeholders}

The sustainability of successful social mobilization is determined by the 'full participation' and level of 'ownership' of the local stakeholders in the planning, implementation, continuous monitoring, and periodic evaluation of the decision-making process, projects, and programmes.

\section{Discussion}

Social mobilization (SM) utilizes the collective strengths of the partnerships of stakeholders and community participation in decision-making to build 'resilience'. In the context of climate change, social mobilization is a tool for the empowerment of individuals and communities, with the skills and capacity, to turn vulnerability to resilience. The goal of SM is to 'turn vulnerability to resilience' through a bottom-up, multi-sectoral, multijurisdictional, and multi-disciplinary participatory approach. This approach establishes partnerships between vulnerable communities and academic institutions (experts from the physical and sciences, economics, health/demographics, management and policy), local stakeholders and capacity building leaders from research institutions, government agencies, and non-profit organizations to use science and policy to implement mitigation measures and strategies for adaptation to climate change (Foufoula-Georgiou, 2013).

SM can impact on vulnerability to adverse effects of climate change through collective, gender-diverse, youth-sensitive, informal, organizational, and institutional initiatives. In the context of reduction of adverse effects of climate change, SM builds capacity and resilience to plan and respond to mitigation measures and strategies to adaptation to climate change. Aggressive $\mathrm{SM}$ is required to change collective behaviour towards the adoption of lifestyles and practices that reduce carbon footprints. This is in order to achieve reduction in the emission of greenhouse gases (GHGs) and mobilize public support for low-carbon climate change policies that focus on green economy, ecological resilience, and building of sustainable communities (Pacific Institute for Climate Change, 2010).

Efficient SM enables social inclusion of all stakeholders, irrespective of socio-economic status, in both the public and private sectors to participate in the decision-making process for 'good governance' in the community (Deutsch, 1969). Community participation in good governance requires political mobilization against social injustice and the development of alternative forms of dispute resolution, such as those associated with community displacements and oil spillages (Naila, et al., n. d.).

Vulnerability to climate change is the degree to which groups, institutions, communities, systems, or population is susceptible to, or unable to cope with, the adverse effects of climate variability, intensity, and change 
(IPCC, 2007). From a health perspective, vulnerability can be defined as the summation of all risks and protective factors that ultimately determine whether individuals, groups, communities and/or regions experience adverse health outcomes due to climate change (Balbus \& Malina, 2009). Social mobilization is a proven potent tool in the successful transfer of health-related knowledge and practices (Babalola et al., 2001), improvement in the performance of village-based health providers with significant increase in the utilization of health services (Gine, et al., 2018).

A study in the Punjab showed that the impact of SM on projects was determined by 'satisfactory' involvement of the target population in the identification of the problems, solutions, monitoring, evaluation, suggestions, and recommendations (Ahmad, 2009).

\section{Conclusion}

Vulnerability to climate change is the degree to which groups, institutions, communities, systems, or populations the Niger Delta region are susceptible to, or unable to cope with, the adverse effects of climate variability, intensity and change. For example, the extensive exposure of the coastal and low-lying areas to sea level rise, and continued exposure to gas flaring and massive emissions of GHGs increase vulnerability of the region to adverse impacts of climate change.

Social mobilization is the tool for the mobilization of public response to threats of vulnerability to climate change. Social mobilization often emerges from a sense of shared grievance and injustice, and it makes visible, alternative ideas and concepts about the forms that society and development should take. SM utilizes the collective strengths of the partnerships of stakeholders and community participation in decision-making to build 'resilience'. It is possible to turn vulnerability to climate change into resilience through social mobilization of partnerships, awareness raising, generation of evidence-based accurate information on local community and regional vulnerability to climate change, capacity building, and utilization of available resources (manpower, money and materials) to support the implementation of participatory public response to reduce vulnerability to adverse impacts of climate change.

Social mobilization is the most sustainable opportunity for efficient and effective empowerment of individuals, communities, and organizations in the Niger Delta region to think and understand their vulnerability to the impacts of climate change; and to organize and build resilience, skills, and capacity to lead happy and healthy lives through participatory bottom-up approach with their own initiative and creativity.

A joint multi-sectoral, multi-jurisdictional, and multi-disciplinary, gender-diverse and youth-sensitive team purposely constituted for social 
mobilization, in the Niger-Delta region, would provide a platform to establish alliances and partnerships between vulnerable communities and academic institutions (experts from the physical and sciences, economics, health/demographics, management and policy), local stakeholders, and capacity building leaders from research institutions, government agencies, and non-profit organizations, with a clear mandate to make the sustainability of the Niger Delta region a top priority. It further demonstrates that it is possible to use science and policy to 'turn vulnerability to resilience'.

Operationally, social mobilization involves advocacy, needs assessment, establishing a community mobilization group (alternative leadership), setting of objectives, climate change communication, identification of vulnerable groups, development of a plan of action (POA) that does not interfere with existing statutory health systems, building alliances and partnerships, community engagement to create awareness of vulnerability, building capacity for identified gaps in resources, implementation of POA, and monitoring and evaluation.

\section{Recommendations}

1. There is an urgent need to perform, review, or update any existing Niger-Delta regional needs assessment of the vulnerability of the communities and the entire ecosystem, especially in the coastal and low-lying areas due to the impact of climate change, to guide regional policies on mitigation measures and adaptation strategies to climate change.

2. A joint multi-sectoral, multi-jurisdictional, and multi-disciplinary, gender-diverse and youth-sensitive team purposely constituted for social mobilization, in the Niger-Delta region, would provide a platform to establish alliances and partnerships between vulnerable communities and academic institutions (experts from the physical and sciences, economics, health/demographics, management and policy), local stakeholders, and capacity building leaders from research institutions, government agencies, and non-profit organizations, with a clear mandate to make the sustainability of the Niger Delta region a top priority. Partnerships and alliances of civil societies should be encouraged to increase "social capital' and build sustainable developmental projects, through the empowerment of the citizens towards the achievement of the sustainable development goals (SDGs) in the Niger Delta region.

3. 3. The Federal and State Governments in the Niger Delta region, should endorse a joint work plan, with supportive policies on mitigation measures and adaptive strategies to climate change, to ensure that social mobilisation turns vulnerability of local communities 
of the threats of climate change to resilience. The goals or specific objectives of the work plan should include building of sustainable communities with reduction of carbon foot prints through social inclusion and full participation of stake holders in the planning, implementation, monitoring, and evaluation.

4. Federal and State Governments, Regional Organizations (e.g. NDDC) Tertiary Institutions and individual Researchers, should develop and engage in adequately funded research agenda, that apply science and policy, for the socio-economic transformation of the Niger Delta region, from vulnerability to resilience to adverse impacts of climate change, in compliance with the Sustainable Development Goals (SDGs).

\section{References:}

1. Ahmad, W., Fiaz, M., Ahmad, M., Hussain, K. \& Fareed, F. (2009). Impact of Social Mobilization efforts on community development for rehabilitation of salt affected and waterlogged lands in tehsil Sahiwal, district Sargodha. Journal of agricultural research.

2. Babalola, S., Sakolsky, N., Vondrasek, C., Mounlom, D., Brown, J., \& Tchupo, J. P. (2001, December). The impact of a community mobilization project on health-related knowledge and practices in Cameroon. Journal of Community Health. 26. 459-477. 10.1023/A:1012511424693.

3. Balbus, J. M. \& Malina, C. (2009). Identifying Vulnerable Subpopulations for Climate Change Health Effects in the United States. Journal of Occupational and Environmental Medicine, 51(1), 33-37. doi: 10.1097/jom.0b013e318193e12e

4. Buggineni, P. (July, 2014). Social Mobilisation, Advocacy and Communication for Nutrition.

5. Cazenave, A. \& Cozannet, G. L. (2014). Sea level rise and its coastal impacts. Earths Future, 2(2), 15-34. doi: 10.1002/2013ef000188

6. Centers for Disease Control and Prevention (n.d.). Community mobilization guide: A community-based effort to eliminate syphilis in the United States. Retrieved March 10, 2020 from, https://www.cdc.gov/stopsyphilis/toolkit/Community/CommunityGui de.pdf (Guidance Document).

7. Crutzen, P. J. (2002). Geology of mankind. Nature, 415(6867), 23-23. doi: 10.1038/415023a

8. Deutsch, K.W. (1969) Implications of Social Mobilization for the Politics of Development. In: Blondel J. (eds) Comparative Government. Palgrave, London. Online ISBN 978-1-349-15318-3 DOI https://doi.org/10.1007/978-1-349-15318-3_6. 
9. Ebegbulem, J. C., Ekpe, D. \& Adejumo, T. O. (2013). Oil Exploration and Poverty in the Niger Delta Region of Nigeria: A critical Analysis. International Journal of Business and Social Science. 4(3): 279 - 287

10. Foufoula-Georgiou, E. (2013). A vision for a coordinated international effort on delta sustainability. IAHS-AISH Proceedings and Reports. 358. 3-11.

11. Federal Ministry of Environment Special Climate Change Unit (2011). National Adaptation Strategy and Plan of Action on Climate Change For Nigeria (NASPA-CCN). November 2011 Federal Ministry of Environment Special Climate Change Unit. November 2011 Electronic version: ISBN 978-0-9878656-56. Book version: ISBN 978-0-9878656-4-9

12. Fund for Peace (2016, December 13). Niger Delta Quarterly Conflict Trends, July to September 2016. Retrieved April 15, 2020 from https://reliefweb.int/report/niger/niger-delta-quarterly-conflict-trendsjuly-september-2016

13. Geldof, L. (1994). Community empowerment: social mobilization in Nigeria. Lagos, Nigeria: UNICEF.

14. Gine, X., Khalid, S., \& Mansuri, G. (2018). The Impact of Social Mobilization on Health Service Delivery and Health Outcomes : Evidence from Rural Pakistan. Policy Research Working Paper; No. 8313. World Bank, Washington, DC. () World Bank. https://openknowledge.worldbank.org/handle/10986/29223 License: CC BY 3.0 IGO

15. Huberman, B., Klaus, T., \& Davis, L. (August 2014). Strategies Guided by Best Practice for Community Mobilization. Retrieved March 10, 2020 from, https://advocatesforyouth.org/resources/healthinformation/strategies-guided-by-best-practice-for-communitymobilization/

16. Ighedosa, SU. (2019). Climate Change: Vulnerability of the Niger Delta Region, in Nigeria. International Journal of Environment and Climate Change, 9(12), 764-788. https://doi.org/10.9734/ijecc/2019/v9i1230156.

17. Intergovernmental Panel on Climate Change (2014). Summary for Policymakers. In Climate Change 2013 - The Physical Science Basis: Working Group I Contribution to the Fifth Assessment Report of the Intergovernmental Panel on Climate Change (pp. 1-30). Cambridge: Cambridge University Press. doi:10.1017/CBO9781107415324.004

18. IPCC (2007). Summary for Policymakers. In: Climate Change 2007: The Physical Science Basis. Contribution of Working Group I to the Fourth Assessment Report of the Intergovernmental Panel on Climate Change [Solomon, S., D. Qin, M. Manning, Z. Chen, M. Marquis, K.B. 
Averyt, M. Tignor and H.L. Miller (eds.)]. Cambridge University Press, Cambridge, United Kingdom and New York, NY, USA.

19. IPCC (2014). Climate Change 2014: Synthesis Report. Contribution of Working Groups I, II and III to the Fifth Assessment Report of the Intergovernmental Panel on Climate Change [Core Writing Team, R.K. Pachauri and L.A. Meyer (eds.)]. IPCC, Geneva, Switzerland, $151 \mathrm{pp}$.

20. Katherine, M. S. (2009). Global Climate Change \& Child Health. Children's Health and the Environment. WHO Training Package for the Health Sector. World Health Organization

21. Lindgren, E., \& Gustafson, R. (2001). Tick-borne encephalitis in Sweden and climate change. The Lancet, 358(9275), 16-18. doi: 10.1016/s0140-6736(00)05250-8

22. McGranahan, G., Balk, D., \& Anderson, B. (2007). The rising tide: assessing the risks of climate change and human settlements in low elevation coastal zones. Environment and Urbanization, 19(1), 17-37. doi: 10.1177/0956247807076960

23. Merem, E., Twumasi, Y., Wesley, J., Isokpehi, P., Fageir, S., Crisler, M., ... Nwagboso, E. (2018). Assessing the Effects of Fuel Based Lighting: The Case of Kerosene Use and Disasters in Nigeria. Public Health Research. 8. 6-23. 10.5923/j.phr.20180801.02.

24. Naila, K., Taherah, Y.H., \& Arif, H. K. (n. d.) (2020). Quantifying the impact of social mobilisation in rural Bangladesh: an analysis of Nijera Kori. Retrieved April 17, 2020 from https://www.google.com/url?sa=t\&rct=j\&q=\&esrc=s\&source=web\& $\mathrm{cd}=1 \& \mathrm{cad}=\mathrm{rja} \& u a c t=8 \& \mathrm{ved}=2 \mathrm{ahUKEwiHh} 52 \mathrm{hzfLoAhUCShUIHdS}$ oBdYQFjAAegQIARAB\&url=http\%3A\%2F\%2Fnijerakori.org\%2F wp-content $\% 2$ Fuploads $\% 2 \mathrm{~F} 2016 \% 2 \mathrm{~F} 03 \% 2 \mathrm{FQuantifying-the-impact-}$ of-social-mobilisation-27th-

December.pdf\&usg=AOvVaw17KAzY58feHIuteKia2Y6K

25. Niger Delta Development Commission (2006). Niger Delta regional development master plan. Port Harcourt, Nigeria.

26. Odjugo, P.A. (2011). Perception of Climate Change in the Niger Delta region of Nigeria. CPED Policy Paper series 2011. Ambik Press ltd. Benin, Nigeria.

27. Omojimite, B. (2011). The Economic Dimensions of the Niger Delta Ethnic Conflicts. African Research Review, 5(5). doi: 10.4314/afrrev.v5i5.5

28. Onokerhoraye, A.G. (2011). Climate change and advocacy on adaptation strategies at the local level in Nigeria. CPED Policy Paper series 2011. Ambik Press ltd. Benin, Nigeria. 
29. Pacific Institute for Climate Solutions (2010). Social Mobilization for Climate Solutions Post-Workshop Summary Report: March 11-12, 2010. Retrieved April 17, 2020 from https://www.google.com/url?sa=t\&rct=j\&q=\&esrc=s\&source=web\& cd=1\&ved=2ahUKEwjysrvvy_LoAhUHUBUIHYTaBrYQFjAAegQI ARAB\&url=https $\% 3 \mathrm{~A} \% 2 \mathrm{~F} \% 2 \mathrm{Fpics}$. uvic.ca\%2Fsites $\% 2 \mathrm{Fdefault} \% 2 \mathrm{~F}$ files $\% 2$ Fuploads $\% 2$ Fpublications $\% 2$ FSocial $\% 2520$ Mobilization $\% 25$ 20Workshop\%2520Report.pdf\&usg=AOvVaw07zC_vDZMg9mV13 SXjed2n

30. Parry, M. (2007). Climate change 2007: impacts, adaptation and vulnerability: contribution of Working Group II to the fourth assessment report of the Intergovernmental Panel on Climate Change. Cambridge: Cambridge University Press. ISBN: 978-0521880107

31. Pascual, M., Rod, X., Ellner, S. P., Bouma, M. J., \& Colwell, R. (2000). Cholera Dynamics and El Nino-Southern Oscillation. Science, 289(5485), 1766-1769. doi: 10.1126/science.289.5485.1766

32. Rodgers, A. \& Vaughan, P. (2002). World Health Report. Reducing risks, promoting healthy life. World Health Organisation, France.

33. Smithson, P. A. (2002). IPCC, 2001: climate change 2001: the scientific basis. Contribution of Working Group 1 to the Third Assessment Report of the Intergovernmental Panel on Climate Change, edited by J. T. Houghton, Y. Ding, D. J. Griggs, M. Noguer, P. J. van der Linden, X. Da. International Journal of Climatology, 22(9), 1144-1144. doi: 10.1002/joc.763

34. Thornes, J. E. (2002). IPCC, 2001: Climate change 2001: impacts, adaptation and vulnerability, Contribution of Working Group II to the Third Assessment Report of the Intergovernmental Panel on Climate Change, edited by J. J. McCarthy, O. F. Canziani, N. A. Leary, D. J. Dokken a. International Journal of Climatology, 22(10), 1285-1286. doi: $10.1002 /$ joc. 775

35. United Nations Children's Fund (2015). Social mobilization. (2015, June 24). UNICEF. Retrieved December 18, 2019 from https://www.unicef.org/cbsc/index_42347.html

36. United Nations Children's Fund (n.d.). Key messages Booklet; The Community Infant and Young Child Feeding Counselling Package. Toolkits. Assessed from toolkits.knowledgesuccess.org on 18th December, 2019.

37. United Nations Climate Change - Summit (2019). Retrieved August 21, 2019, from https://www.un.org/en/climatechange/pressmaterials.shtml

38. United Nations Framework Convention on Climate Change (2011). Fact Sheet: Climate Change Science - the status of climate change 
science today. Retrieved December 4, 2019, from https://unfccc.int/files/press/backgrounders/application/pdf/press_fact sh_science.pdf

39. United Nations Framework Convention on Climate Change. (n.d.) (2019). Glossary of climate change acronyms and terms. Retrieved August 24, 2019, from https://unfccc.int/process-and-meetings/theconvention/glossary-of-climate-change-acronyms-and-terms

40. UN-Habitat Regional Office for Asia \& the Pacific, UN-Habitat Fukuoka Office (2008). Peoples process in post-disaster, and postconflict recovery and reconstruction. Fukuoka, Japan.

41. World Health Organization (2019). Social Mobilization. (2019, February 8). World Health Organisation. Retrieved December 19, 2019, from https://www.who.int/healthpromotion/socialmobilization/en/

42. World Health Organisation (2012, August 24). Preparedness. RetrievedDecember20,2019,fromhttp://www.who.int/environmental_ health_emergencies/preparedness/en/

43. World Health Organization (2009). Protecting health from climate change: global research priorities. Geneva, Switzerland.

44. World Health Organization (2003). Climate change and human health: risks and responses. Geneva, Switzerland. ISBN 9241590815

45. World Meteorological Organization (n.d.) (2019). Frequently Asked Questions (FAQs). Retrieved December 3, 2019 from http://www.wmo.int/pages/prog/wcp/ccl/faqs.php 